EGU2020-14843

https://doi.org/10.5194/egusphere-egu2020-14843

EGU General Assembly 2020

(c) Author(s) 2020. This work is distributed under

the Creative Commons Attribution 4.0 License.

\title{
Towards a probabilistic assessment of sediment yields in a mountainous area: the case study of Valle Camonica
}

\author{
Gian Battista Bischetti ${ }^{1,2}$, Paolo Sala ${ }^{1}$, Paolo Fogliata ${ }^{1}$, Emanuele Morlotti ${ }^{1}$, and Alessio Cislaghi ${ }^{1,2}$ \\ ${ }^{1}$ Department of Agricultural and Environmental Sciences (DiSAA), University of Milan, Milan, Italy (bischetti@unimi.it) \\ ${ }^{2}$ Centre of Applied Studies for the Sustainable Management and Protection of Mountain Areas (Ge.S.Di.Mont), University of \\ Milan, Edolo (BS), Italy
}

Sediment production and delivery are hillslope processes characterized by significant variability and uncertainty, especially in mountain drainage catchments. Although sediments can be originated from several phenomena, such as slope instabilities, soil erosion and streambank failures, rainfall-induced landsliding, eventually turned into debris flows, is the dominant mechanism producing and conveying huge volumes of solid material to downstream areas through the channel network and therefore causing an increase of flood frequency.

Such landslide-derived mechanisms cause damage, directly and indirectly, to public and/or private properties and infrastructure on alluvial fans that are basically due to the increase of clogging probability of bridges, instream sediment accumulation, and significant geomorphological change. Identifying the sediment upstream source areas and quantifying a probability distribution of the mobilized- and delivered-sediment volume, then, is crucial for the protection of downstream areas. However, such purpose still remain extremely challenging because of scarcity, or even lack, of time-consuming direct measurements that are generally carried out at small scale and cover short time periods.

On this background, this work proposes a simplified procedure to estimate a probability distribution of the sediment yields combining: (i) rainfall intensity-duration-frequency (IDF) relationships for estimating synthetic precipitation with specific return time; (ii) a threedimensional slope stability model to assess the rainfall-induced shallow landslides susceptibility; (iii) a connectivity index for mapping the probability of sediment delivery; and (iv) a simple hydrological model based on SCS-CN method to estimate the flood peak, and furthermore the probability distribution of sediment flux. The procedure requests low-resolution maps, usually available at the regional scale, such as digital elevation model, land cover, geology, lithology, and IDF curves, and represents a planning tool for climate and land cover change mitigation that can be extremely useful for forest managers, hydraulic engineering and watershed planners.

The procedure was tested on several small mountainous headwater catchments in Valle Camonica, located into the Central Italian Prealps, mostly covered by forests, with settlements on alluvial fans, and prone to shallow landslide, debris flood, and debris flow. It was qualitatively validated on the landslide inventory and the mapped flood areas, showing comparable results. 
